\title{
An early breathing disorder in a newborn: Jeune syndrome
}

\author{
Fatma Narter ${ }^{1}$, Ozlem Turkoglu ${ }^{2} *$, Hakan Sarbay $^{3}$, Muferret Erguven $^{3}$
}

\begin{abstract}
Introduction: Jeune syndrome affects an estimated 1 in 100.000 to 130.000 people. The syndrome causes breathing disorders accompanying upper and lower respiratory tract infections in consequence of a respectively small and narrow thoracic cage instead of the normal stance.

Case: Here we report a male newborn with narrow thoracic cage and short limbs. Radiological evaluation of the chest radiograph showed short ribs due to congenital abnormalities. Findings in the X-Ray computed tomography were decreased antero-posterior diameter of chest cavity accompanying short-rib dysplasia and respectively shallow acetabular cavity. Abdominal ultrasonography was also made and findings were small kidneys in bilateral stance accompanied by pelvicaliectasis and milimetric intraparenchymal liver calcification. Following the recurrent lower respiratory tract infections, the baby expired within fourth month. The final diagnosis was Jeune syndrome.

Conclusion: Jeune syndrome is a rare seen congenital anomaly. Radiological evaluation is essential for diagnosis. Characteristic finding include many skeletal abnormalities on costochondral junctions, clavicles, iliac bones, long bones of the extremities, and phalanges of both hands and feet. About $\% 60$ to $\% 70$ of children with this condition die from respiratory failure since they are at greater risk. Early detection is key for decreasing the incidence of death from this syndrome.
\end{abstract}

Keywords: Jeune syndrome, short-rib dysplasia, newborn

\section{Introduction}

Jeune syndrome (asphyxiating thoracic dystrophy) was first reported in 1955 by Jeune et al (1).

Respiratory distress is caused by the dystrophic narrow thorax that restricts the growth and expansion of the lungs. Other accompanying anomalies can be short or cone shaped bones and extra fingers or toes (polydactyly).

Newborns may develop liver diseases, fluid-filled sacs (cysts) in pancreas and retinal dystrophy that causes vision loss. They may live only into infancy or early childhood, whereas those with mild chest bone dysplasia may live into adolescence or adulthood.

It is also possible for life-threatening kidney abnormalities, heart defects and subglottic stenosis to arise after infancy

\section{Case}

Our case is the second child of mother married to her cousin at 19 years of age. Labor was spontaneous on 29 week 6/7 day of gestational period.
Male infant was $1204 \mathrm{~g}$ with abnormally short extremities. He was transferred to the newborn intensive care unit due to the serious respiratory distress. Physical examination showed abnormal narrow thorax in addition to short extremities. The Jeune syndrome was considered for the differential diagnosis. The baby was put on continuous positive airway pressure and surfactant was given through an endotracheal tube for once. Radiological evaluation of chest radiograph showed short ribs with wide spectrum of abnormalities. In X-Ray computed tomography was shown decreased anterio-posterior diameter of chest cavity accompanying short-rib dysplasia and shallow acetabular cavity (Figure 1).

During echocardiogram session a thin patent ductus arteriosus was seen. Abdomen ultrasonography detected bilateral small kidneys accompanied by left pelvi-caliectasis (Figure 2) and millimetric intraparenchymal liver calcification. Following the recurrent lower respiratory tract infections, the baby expired within fourth month.

Received: 07-12-2015, Accepted 22-12-2015, Available Online 15-02-2016

1 Dept. of Pediatrics Division of Neonatology, Kartal Dr Lütfi Kirdar Education and Research Hospital, Istanbul, Turkey.

2 Dept. of Radiology, Kartal Dr Lutfi Kırdar Education and Research Hospital, Istanbul, Turkey.

3 Dept. of Pediatrics, Umraniye Education and Research Hospital, Istanbul, Turkey.

*Corresponding Author: Ozlem Turkoglu E-mail: ozlemkolcak@hotmail.com 


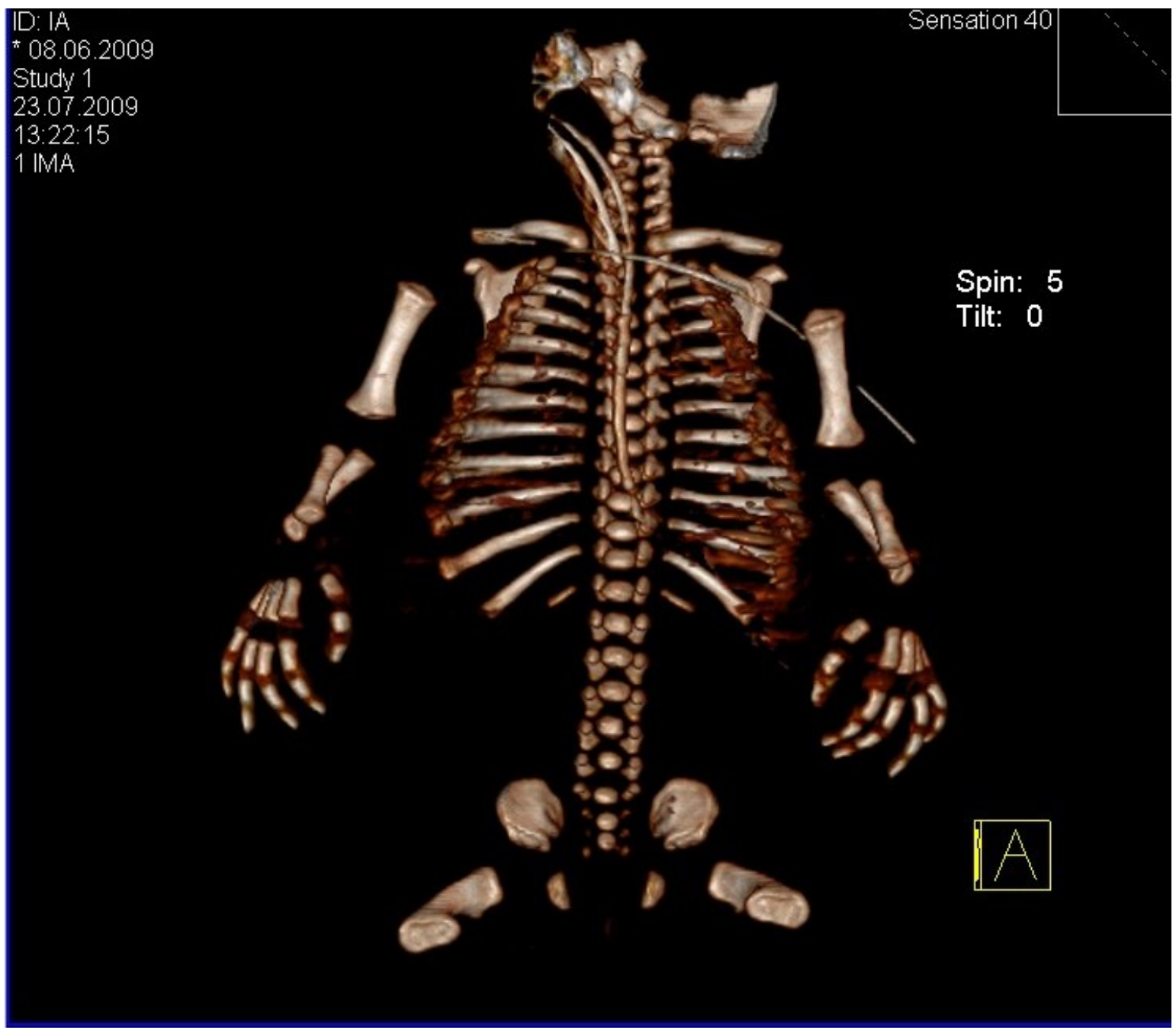

Figure 1. Decreased antero-posterior diameter of chest cavity and shallow acetabular cavity on 3D CT

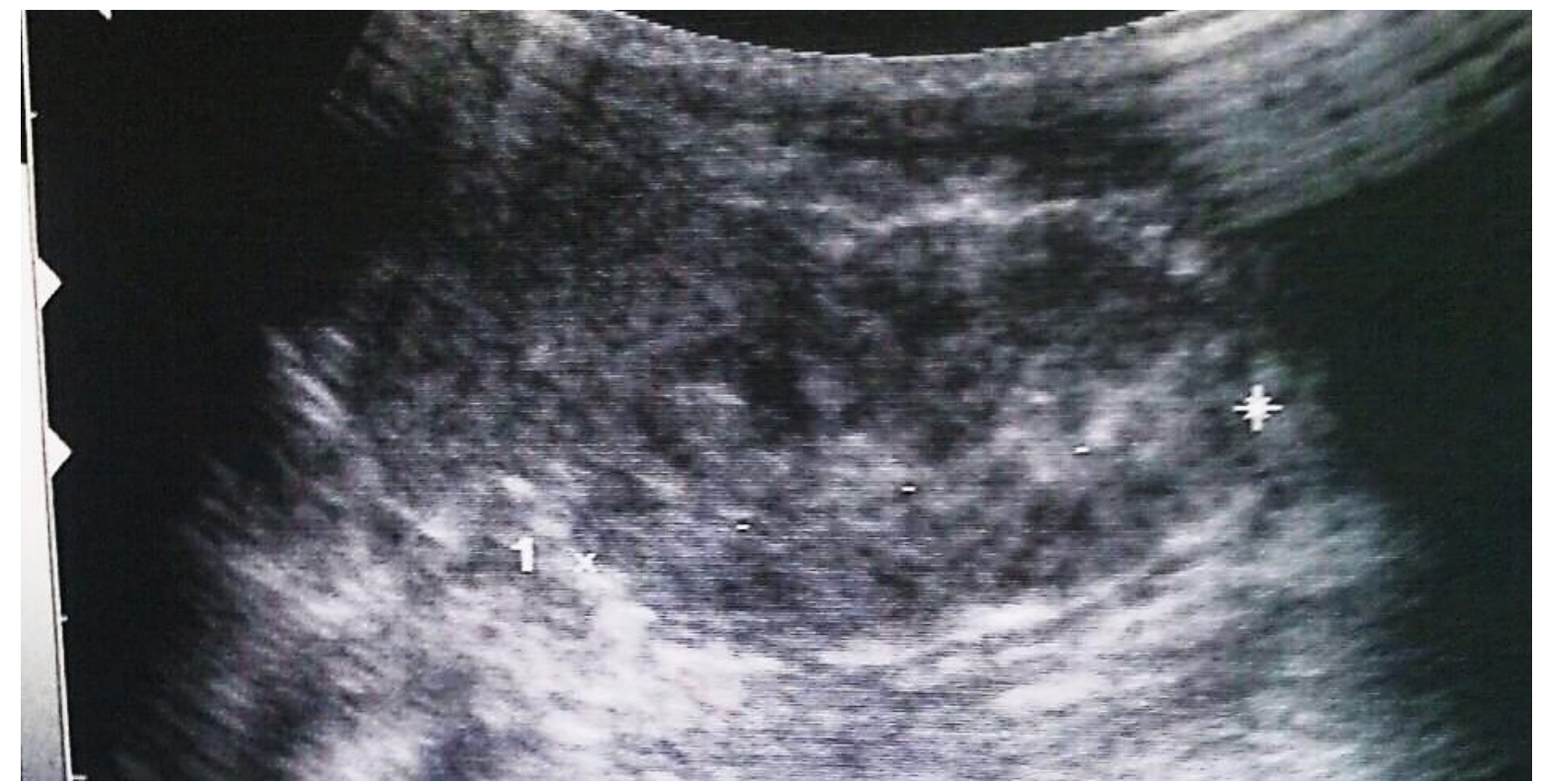

Figure 2. Left pelvi-caliectasis 


\section{Discussion}

Jeune syndrome has autosomal recessive inheritance and transmitted on the short arm of 12th chromosome (3). The prevalence of Jeune's syndrome is 1 in 100.000 to 130.000 . Radiological evaluation is essential for diagnosis. Characteristic findings include a narrow, bell-shaped thorax with short ribs and irregular bulbous costochondral junctions. Typical radiographic findings include a narrow bell-shaped thorax with short horizontally oriented ribs with irregular costochondral junctions, elevated clavicles, short iliac bones with a typical trident appearance of the acetabula, relatively short and wide long bones of the extremities and hypo-plastic phalanges of both hands and feet with cone-shaped epiphyses (5-10).

Costachondral irregularity which is similar to rachitic rosary is caused by irregular endochondral osteogenesis. Unusual pelvic bones are small and hypo-plastic $(3,5)$. Horizontal diameter of iliac bones are short and acetabular angle is narrow (trident acetabulum). Epiphysis of femur heads can show early ossification. Vertebra and skull bones are not effected (6).

29 weeks-old male premature baby with his short extremities was diagnosed as achondroplasia on his first impression. Later it was for narrow bell shaped thorax and short extremities becoming a reason for the certain diagnosis of the Jeune syndrome in subsequent to first impression. In the consequence of the observation process mother was not followed up effectually during pregnancy. In theory, it also indicates that $40-50 \%$ of Jeune syndrome was diagnosed within the first month after delivery $(4,5)$.

Generally newborns with the Jeune syndrome face respiratory failure resulting death. However there are some reported cases without any respiratory involvement (11). In most of the cases the survival of the diagnosed patient depends on thorax dystrophy.

Our case suffered from recurrent respiratory infections and died on the 15th week after his birth. Hypoplastic ribs and narrow thoracic cage result in nonexpansible lungs. Autopsy specimen made clear of disturbed pulmoner vascular structure and pulmonary hypertension. It was shown that bronchial and alveolar structures were not affected (12).

Children with this syndrome may encounter renal dysplasia (6). Mortality depends on cystic changes and diffuses interstitial fibrosis (13-17). Abdominal USG examination of our case reported bilateral small kidneys and pelvi-caliectasis of left kidney.

Laboratory measurements of urea and creatinine were in the normal limits.
In our case we mentioned a millimetric intraparenchymal liver calcification. In literature liver involvement had been reported (17). Liver involvement may progress to cirrhosis (13). According to this information blood levels of transaminase and gamma glutamyl transferase were taken into account (17). Transaminase levels were normal. The most common histopathological anomaly seen with liver involvement is portal fibrosis and bile canaliculus proliferation (2). Sonography didn't detect any abnormality of portal structures. Pancreatic cysts and exocrine insufficiency are very rare (2). We didn't observe either.

In differential diagnosis of Jeune syndrome there are chondroectodermal dysplasia (Ellis-van Creveld syndrome) and thoraco-laryngo-pelvic dysplasia (Barnes syndrome). All of the cases of Ellis-van Creveld syndrome are accompanied by polydactyl and ectodermal dysplasia (18). Our case didn't have both features. Barnes syndrome includes bell shaped thorax and laryngeal stenosis together (19). In our case there was no laryngeal stenosis.

Jeune syndrome is a rare congenital abnormality and differential diagnosis is difficult due to its characteristic features. In most of the cases the mortality is as a result of respiratory failure. Therefore early diagnosis to decrease mortality depends on doctor's recognising the concerned symptoms.

Financial Support: This research received no specific grant from any funding agency, commercial or notfor- profit sectors.

Conflict of interest: The authors declare no potential conflicts of interest with respect to the research, authorship, and/or publication of this article.

\section{References}

1. Jeune M, Beraud C, Carron R. Dystrophie thoracique asphyxiante de caractere familial. Arch Fr Pediatr 1955; 12: 886-91.

2. Vries J, Yntema JL, Van Die CE, Crama N, Cornelissen AM, Hamel BCJ. Jeune syndrome: description of 13 cases and proposal for follow-up protocol. Eur J Pediatr 2009; May 10. [Epub ahead of print].

3. Nagai T, Nishimura G, Kato R, Hasegawa T, Oashi $H$, Fukushima Y. Del [12] [p11.21p12.2] associated with asphyxiating thoracic dystrophy or chondroectodermal dysplasia-like syndrome. AM J Med Genet 1995; 55: 16-8.

4. Poggiani C, Gasparoni MC, Mangili G, Colombo A. Asphyxiating thoracic dysplasia in a lethal form:radiological and sonographic findings. Minerva Pediatr 2000; 52: 63-7.

5. Barnes ND, Hull D, Simons JS [1969] Thoracic dystrophy. Arch Dis Child 44:11-17. doi:10.1136/adc.44.233.11 
6. Cortina H, Beltran J, Olague R et al [1979] The wide spectrum of the asphyxiating thoracic dysplasia. Pediat Radiol 8:93-99.

7. Friedman JM, Kaplan HG, Hall JG [1975] The Jeune syndrome [asphyxiating thoracic dystrophy] in an adult. Am J Med 59:857-862.

8. Hennekam RCM, Beemer FM, Gerards LJ, Cats B [1983] Thoracic pelvic phalangeal dystrophy [Jeune syndroom] Tijdschr Kindergeneeskd 51:95-100

9. Herdman RC, Langer LO [1968] The thoracic asphyxiant dystrophy and renal disease. Am J Dis Child 116:192-201

10. Hudgins L, Rosengren S, Treem W, Hyams J [1992] Early cirrhosis is survivors with Jeune thoracic dystrophy. J Pediatr 120:754-756.

11. Kozlowski K, Masel j. Asphyxiating thoracic dystrophy without respiratory disease: report of two cases of the latent form. Pediatr Radiol 1976; 5: 30-3.

12. Williams AJ, Vawter G, Reid LM. Lung structure in asphyxiating thoracic dystrophy. Arch Pathol Lab Med $1984 ; 108: 658-61$.
13. Verma A, Gurudatta HS. Jeune syndrome. Indian Pediatr 2004; 41: 954-5.

14. Donaldson MDC, Warner AA, Trompeter R, Haycock GB, Chantler C. Familial juvenile nephronophtisis, Jeune's syndrome, and associated disorders. Arch Dis Child 1985; 60: $426-34$

15. Amirou M, Bourdat-Michel G, Pinel N, Huet G, GaultierJ, Cochat P. Successful renal transplantation in Jeune's syndrome type 2. Pediatr Nephrol 1988; 12: 293-4.

16. Özçay F, Derbent M, Demirhan B, Tokel K, Saatçi U. A family with Nephrol 2001; 16[8]:623-6. Jeune-sydrome. Pediar

17. Labrune P, Fabre M, Troche P, et al. Jeune sydrome and liver disease: report of the three cases treated with ursodeoxycholic acid. Am J med Gene 1999; 87: 324-8.

18. Ellis RW, van Creveld SA. A sydrome chracterised by ectodermal dysplasia, polydactyly, chondroplasia ad congenital morbus cordis; report of three cases. Arch Dis Child 1940; 15: 65-84.

19. Burn J, Hall C, Marsden D, Mathew DJ. Autosomal domiant thoracolaryngopelvic dysplasia: Barnes syndrome. J Med Genet 1986; 23: 345-9.

Copyright (C) 2014 The Author(s); This is an open-access article distributed under the terms of the Creative Commons Attribution License (http://creativecommons.org/licenses/by/4.0), which permits unrestricted use, distribution, and reproduction in any medium, provided the original work is properly cited. All Rights reserved by international journal of Medical Science and Discovery. 